\title{
Efektifitas Selimut Elektrik dalam Meningkatkan Suhu Tubuh Pasien Post Seksio Sesarea yang Mengalami Hipotermi
}

\author{
Mutiara Dewi Listiyanawati ${ }^{1}$, Noriyanto ${ }^{2}$ \\ Program Studi Ilmu Keperawatan Universitas Alma Ata Yogyakarta1,2 \\ mudeli43@gmail.com ${ }^{1}$, noriyanto2015@gmail.com²
}

\begin{abstract}
ABSTRAK
Latar Belakang: Operasi bedah seksio sesarea mempunyai risiko mengganggu intregritas atau keutuhan tubuh bahkan dapat merupakan ancaman kehidupan pasien. Pasien post operasi seksio sesarea dapat mengalami hipotermi yang disebabkan oleh suhu yang rendah di kamar operasi, luka yang terbuka dan aktifitas otot yang menurun akibat efek anestesi spinal, sehingga dapat memperlama proses penyembuhan luka operasi. Salah satu penatalaksanaan untuk menangani kasus hipotermi di ruang pemulihan adalah dengan penggunaan selimut kain atau selimut elektrik, namun penggunaan selimut tersebut di RSUD Dr. Tjitrowardojo Purworejo belum dijadikan standar prosedur operasional.

Tujuan: mengetahui efektifitas penggunaan selimut elektrik terhadap peningkatan suhu tubuh pasien post operasi seksio sesarea yang mengalami hipotermia di ruang pemulihan RSUD Dr. Tjitrowardojo Purworejo

Metode: Jenis penelitian ini adalah quasi experiment research dengan desain two-group pre-post test design.Pengambilan sampel dilakukan di ruang pemulihan RSUD Dr. Tjitrowardojo Purworejo. Teknik pengambilan sampel menggunakan purposive sampling dengan jumlah sampel keseluruhan 36 orang, dibagi menjadi 2 kelompok dimana 18 orang diberikan intervensi penggunaan selimut elektrik dan 18 intervensi selimut kain. Uji statistik data menggunakan uji Independent Sample t Test. Hasil: Hasil penelitian diperoleh rata-rata peningkatan suhu tubuh sebelum dan sesudah penggunaan selimut elektrik sebesar $1,544^{\circ} \mathrm{C}$ dan rata-rata peningkatan suhu tubuh sebelum dan sesudah penggunaan selimut kain sebesar $0,856^{\circ} \mathrm{C}$ dengan $p$-value $0,001(<0,05)$.

Kesimpulan: penggunaan selimut elektrik lebih efektif terhadap peningkatan suhu tubuh pasien post seksio sesarea yang mengalami hipotermi ringan dibandingkan dengan penggunaan selimut kain.

Kata kunci: Hipotermi, Seksio Sesarea, Selimut Elektrik
\end{abstract}

\begin{abstract}
Background: Caesarean section surgery has a risk of disrupting the integrity or wholeness of the body and may even be a threat to the patient's life. Postoperative caesarean section can experience hypothermia caused by low temperatures in the operating room, open wounds and decreased muscle activity due to the effects of spinal anesthesia, so as to prolong surgical wound healing. One of the management to handle hypothermia case in recovery room is by using blanket of cloth or electric blanket, but the use of blanket in Dr. Tjitrowardojo hospital hasn't been made standard operational procedure.
\end{abstract}

Objective: This study aimed to determine the effectiveness of electric blanket to increase the body temperature of post operative cesarean section with hypothermia in recovery room Dr. Tjitrowardojo hospital.

Methods: This type of this research is quasi experiment research with two-group design pre-post test design. Sampling was conducted in recovery room Dr. Tjitrowardojo hospital. The total sample number of 36 samples taken by using purposive sampling, divided into 2 groups where 18 people were given the intervention of the use of electric blanket and 18 interval of cloth blanket. The analysis of statistic data used Independent Sample t Test.

Results: The result showed that the average of increasing body temperature before and after the use of electric blanket was $1.544^{\circ} \mathrm{C}$ and the average of increasing body temperature before and after the use of cloth blanket was 0,856 $\mathrm{C}$ with p-value 0,001 $(<0,05)$.

Conclusion: Electric blanket wereshown to be an effective increase body temperature of post-cesarean section who have mild hypothermia compared with the use of cloth blanket.

Keywords: Hypothermia, Caesarean Section, Electric Blanket 


\section{PENDAHULUAN}

Pembedahan elektif maupun kedaruratan adalah peristiwa kompleks yang biasanya menjalani prosedur mencakup penggunaan anestesi lokal, regional, atau umum (Sjamsuhidajat \& De Jong, 2010). Sebagian besar tindakan seksio sesarea dilakukan dengan anestesi spinal atau epidural. Seksio sesarea yang dilakukan dengan indikasi ukuran janin terlalu besar, kelainan letak janin, denyut jantung janin yang tidak normal, kelainan plasenta dan tali pusat, kelainan kontraksi rahim, adanya hambatan jalan lahir (mioma uteri atau tumor), ketuban pecah dini, derajat gawat janin dan ibunya harus dievaluasi dalam menentukan jenis anestesi yang akan dilakukan (Wiknjosatro, 2007; Myles, 2009; Saifuddin, 2010; Lowdermilk, 2010).

Tindakan bedah atau prosedur operasi memiliki risiko kerusakan integritas atau keutuhan tubuh bahkan dapat merupakan ancaman kehidupan pasien. Pasien pasca bedah dapat mengalami hipotermi yang dapat terjadi pada periode peri-operasi hingga berlanjut pada periode pasca operasi di ruang pemulihan, sebagai akibat sekunder dari suhu yang rendah di ruang operasi, infus dengan cairan yang dingin, inhalasi dengan gas yang dingin, kavitas atau luka yang terbuka, aktivitas otot yang menurun, usia yang lanjut atau agen obatobatan yang digunakan, seperti anestesi dan vasodilator (Smeltzer, 2002).

Hipotermia didefinisikan sebagai keadaan dimana suhu tubuh kurang dari $36^{\circ} \mathrm{C}$ dan dapat terjadi sebelum, selama, atau setelah operasi (Sessler, 2014). Hipotermia pasca operasi dapat menyebabkan berbagai efek fisiologis yang merugikan (Shen et al, 2015). Penatalaksanaan hipotermia yang dapat dikerjakan meliputi tindakan non farmakologis serta farmakologis. Teknik terapi non farmakologis dapat dilakukan dengan memberikan selimut hangat, mengatur suhu lingkungan yang memadai, serta menggunakan penghangat cairan untuk tranfusi dan cairan lain (Sjamsuhidajat \& De Jong, 2010).

Ruang pemulihan di RSUD Dr. Tjitrowardojo Purworejo mempunyai selimut elektrik dengan menggunakan sumber tenaga listrik yang bisa digunakan untuk menghangatkan tubuh pada pasien post operasi yang mengalami hipotermi. Alat tersebut sering digunakan pada pasien post seksio sesarea, dimana sebelumnya hanya menggunakan selimut kain. Berdasarkan studi pendahuluan peneliti di ruang pemulihan RSUD Dr. Tjitrowardojo pada bulan Mei 2017, dari 10 pasien post operasi seksio sesarea terdapat 8 pasien yang mengalami hipotermi ringan. Hasil pengukuran peningkatan suhu tubuh pada penggunaan selimut elektrik terhadap 4 pasien hipotermi ringan menunjukkan hasil kenaikan rata-rata $1,80 \mathrm{C}$ sedangkan pada 4 pasien selimut kain mampu menaikkan suhu tubuh pasien rata-rata 0,60C. Penggunaan selimut elektrik mampu meningkatkan suhu tubuh lebih cepat dibandingkan dengan selimut kain pada pasien post operasi seksio sesarea.

Penelitian ini dilakukan untuk mengetahui sejauh mana efektifitas penggunaan selimut elektrik dalam meningkatkan suhu tubuh pasien post operasi seksio sesarea dengan hipotermi di ruang pemulihan. Manfaat yang bisa didapatkan yaitu sebagai acuan untuk pembuatan standar prosedur operasional rumah sakit dalam penatalaksanaan pasien di post operasi seksio sesarea dengan hipotermi di ruang pemulihan.

\section{METODE}

Jenis penelitian yang digunakan adalah quasi experiment research dengan desain two-group pre-post test design. Pengambilan sampel dilakukan di ruang pemulihan RSUD Dr. Tjitrowardojo Purworejo. Teknik pengambilan sampel menggunakan purposive sampling dengan kriteria inklusi adalah pasien post seksio sesarea dengan anatesi spinal yang mengalami hipotermi ringan dengan suhu $34-36^{\circ} \mathrm{C}$ dan bersedia untuk menjadi responden. Kriteria eksklusi dalam penelitian ini adalah pasien post seksio sesarea yang harus segera pindah ke ruang ICU.

Jumlah sampel 36 pasien dibagi menjadi 2 kelompok, dimana 18 pasien 
diberikan intervensi penggunaan selimut elektrik dan 18 pasien diberikan intervensi penggunaan selimut kain selama 60 menit setelah tindakan post seksio sesarea. Selimut elektrik yang digunakan yaitu selimut elektrik merk Equator dengan selimut pemanas berbahan polypropylene non-woven mempunyai panjang $203 \mathrm{~cm}$ dan lebar $101 \mathrm{~cm}$. Saat dilakukan intervensi, selimut elektrik diatur pada suhu alat $44^{\circ} \mathrm{C}$. Selimut kain yang digunakan terbuat dari bahan katun dengan motif garis-garis lurus mempunyai ukuran panjang $180 \mathrm{~cm}$, lebar $150 \mathrm{~cm}$ dan ketebalan $0,2 \mathrm{~cm}$.

Pengumpulan data dilakukan dengan cara mengukur suhu tubuh pasien sebelum dan setelah intervensi dengan menggunakan alat thermometer axila digital. Uji statistik data menggunakan uji Independent Sample $t$ Test dengan tingkat signifikan 5\%. Penelitian dilakukan pada 20 Mei sampai 3 Juni 2017.

\section{HASIL DAN PEMBAHASAN}

1. Deskripsi peningkatan suhu tubuh pasien post seksio sesarea yang diberikan selimut elektrik dan selimut kain di ruang pemulihan RSUD Dr Tjitrowardojo Purworejo

Tabel 1. Deskripsi Peningkatan Suhu Tubuh Pasien Post Seksio Sesarea

\begin{tabular}{lcccc}
\hline Variabel & Mean & Median & SD & Min - Max \\
\hline $\begin{array}{l}\text { Selimut } \\
\text { Elektrik }\end{array}$ & 1.54 & 1.40 & 0.36 & $1.20-2.30$ \\
$\begin{array}{l}\text { Selimut } \\
\text { Kain }\end{array}$ & 0.85 & 0.8 & 0.15 & $0.70-1.30$ \\
\hline
\end{tabular}

Sumber: Data Primer, 2017

Tabel 1 menunjukkan bahwa ratarata peningkatan suhu tubuh pada pasien post seksio sesarea yang diberikan intervensi penggunaan selimut elektrik adalah $1,54^{\circ} \mathrm{C}$ dan rata-rata peningkatan suhu tubuh pasien post seksio sesarea yang diberikan intervensi penggunaan selimut kain adalah $0,85^{\circ} \mathrm{C}$.

Penelitian ini menunjukkan bahwa pemanasan aktif dengan penggunaan selimut elektrik selama 60 menit post seksio sesarea di ruang pemulihan dapat meningkatkan suhu tubuh lebih cepat dibandingkan dengan penggunaan selimut kain.

2. Uji beda rerata suhu tubuh pada pasien post seksio sesarea yang mengalami hipotermi ringan sebelum dan sesudah intervensi penggunaan selimut elektrik dan selimut kain.

Tabel 2. Uji Beda Rerata Peningkatan Suhu Tubuh Sebelum dan Sesudah Intervensi

\begin{tabular}{lcccc}
\hline Perlakuan & \multicolumn{2}{c}{ Rerata Suhu $\left({ }^{\circ} \mathrm{C}\right)$} & Mean & $\begin{array}{c}\text { p- } \\
\text { value }\end{array}$ \\
\hline $\begin{array}{l}\text { Selimut } \\
\text { Elektrik }\end{array}$ & 34.68 & 36.23 & 1.54 & 0.00 \\
$\begin{array}{l}\text { Selimut } \\
\text { Kain }\end{array}$ & 34.92 & 35.78 & 0.85 & 0.00 \\
$\quad$ & & & & \\
\hline
\end{tabular}

Sumber: Data Primer, 2017

Berdasarkan tabel 2, hasil uji Paired Sample t Test diperoleh hasil peningkatan suhu tubuh pada kedua kelompok intervensi penggunaan selimut yaitu menunjukkan hasil yang signifikan. Suhu tubuh kelompok intervensi penggunaan selimut elektrik sebelum perlakuan adalah $34,68^{\circ} \mathrm{C}$ dan sesudah perlakuan mengalami peningkatan rata-rata suhu $1,54^{\circ} \mathrm{C}$ menjadi $36,23^{\circ} \mathrm{C}$. Suhu tubuh kelompok intervensi penggunaan selimut kain sebelum perlakuan adalah $34,92^{\circ} \mathrm{C}$ dan sesudah perlakuan mengalami peningkatan rata-rata suhu $0,85^{\circ} \mathrm{C}$ menjadi $35,78^{\circ} \mathrm{C}$. Berdasarkan perbandingan ratarata peningkatan suhu menunjukkan bahwa penggunaan selimut elektrik memiliki peningkatan suhu lebih besar dibandingkan penggunaan selimut kain (tabel 1).

Hasil penelitian Torrossian, et al (2016) menunjukkan bahwa penggunaan selimut BARRIER EasyWarm pada tahap preoperative, perioperative dan postoperative signifikan meningkatkan suhu tubuh. Selimut diberikan kepada pasien 30 menit sebelum proses anestesi. Rerata suhu tubuh pada tahap postoperative berbeda signifikan antara kelompok intervensi dengan kelompok kontrol $(36,3 \mathrm{C}, \mathrm{SD} \pm 0.5$, vs $36,0 \mathrm{C} \mathrm{SD} \pm 0.5$, dengan nilai $p$ masing-masing 0,01). Kejadian hipotermia pada tahap postoperative signifikan lebih rendah 
pada kelompok intervensi daripada kelompok kontrol ( $24 \%$ vs $49 \%$ dengan nilai $\mathrm{p}$ masing-masing 0,01 ).

Hal ini menunjukkan bahwa penggunaan selimut elektrik pada rangkaian proses operasi yang menggunakan anestesi spinal dapat membantu mengurangi resiko hipotermi pada pasien saat di ruang pemulihan.

3. Uji beda rerata peningkatan suhu tubuh pada pasien post seksio sesarea yang mengalami hipotermi ringan sebelum dan sesudah intervensi penggunaan selimut elektrik dan selimut kain.

Tabel 3 menunjukkan bahwa rerata peningkatan suhu tubuh pada pasien post seksio sesarea dengan perlakuan penggunaan selimut elektrik adalah $1,54^{\circ} \mathrm{C}$ dan rerata peningkatan suhu tubuh pada pasien post seksio sesarea dengan perlakuan penggunaan selimut kain adalah $0,85^{\circ} \mathrm{C}$.

Tabel 3. Uji Beda Rerata Peningkatan Suhu Tubuh

\begin{tabular}{lccc}
\hline Perlakuan & $\begin{array}{c}\text { Rerata } \\
\text { Peningkatan } \\
\text { Suhu Tubuh }\left({ }^{\circ} \mathrm{C}\right)\end{array}$ & $\begin{array}{c}\mathbf{t} \\
\text { hitung }\end{array}$ & $\begin{array}{c}\text { p- } \\
\text { value }\end{array}$ \\
\hline $\begin{array}{l}\text { Selimut } \\
\text { Elektrik }\end{array}$ & 1,54 & 7,490 & 0,001 \\
$\begin{array}{l}\text { Selimut } \\
\text { Kain }\end{array}$ & 0,85 & & \\
\hline
\end{tabular}

Sumber: Data Primer, 2017

Hasil uji perbandingan kedua rerata peningkatan suhu tubuh menggunakan uji Independent Sampel t Test diperoleh hasil $\mathrm{t}=7,490$ dengan $\mathrm{p}=0,001$. Hasil menunjukkan bahwa ada perbedaan signifikan pada rerata peningkatan suhu tubuh pasien post seksio sesarea dengan penggunaan selimut elektrik dan penggunaan selimut kain. Hal ini membuktikan bahwa penggunaan selimut elektrik pada pasien post seksio sesarea yang mengalami hipotermi ringan lebih efektif dalam meningkatkan suhu tubuh dibandingkan penggunaan selimut kain di ruang pemulihan RSUD Dr. Tjitrowardojo Purworejo.

Penggunaan selimut elektrik menggunakan udara yang dipanaskan dan dialirkan melalui selang dan selimut (konveksi) menyebabkan kenaikan suhu tubuh sebagai akibat terpapar udara panas dan mencegah kehilangan panas tubuh (Robinson, 2012). Hasil penelitian Kesuma (2013) mengenai penggunaan selimut tebal dan lampu penghangat pada pasien pasca bedah sectio caesaria yang mengalami hipotermi di ruang pemulihan RSUD Sanjiwani Gianyar menunjukkan bahwa pasien hipotermi yang diberikan penghangat dari luar tubuh memiliki peningkatan suhu yang lebih besar dibandingkan dengan selimut tebal. Selimut kain tebal hanya membungkus atau melindungi pasien dari kehilangan panas yang lebih parah dan proses penghangatan hanya mengandalkan produksi panas dari dalam tubuh saja. Selimut hanya membantu mencegah keluarnya panas yang telah diproduksi di dalam tubuh dan tidak terjadi perpindahan panas dari selimut kain tebal ke dalam tubuh pasien.

Perbedaan antara penelitian Kesuma (2013) dengan yang dilakukan peneliti adalah penggunaan alat untuk meningkatkan suhu tubuh yaitu lampu penghangat dan selimut elektrik. Penggunaan lampu penghangat menggunakan radiasi panas dan yang diukur adalah lama waktu untuk mencapai suhu tubuh kembali ke suhu normal $36^{\circ} \mathrm{C}$ dengan rata-rata suhu sebelum perlakuan $34,06^{\circ} \mathrm{C}$. Hasil penelitiannya dibutuhkan waktu 49,06 menit untuk mencapai suhu normal tubuh dengan peningkatan $1,9^{\circ} \mathrm{C}$. Sedangkan peneliti menggunakan selimut elektrik dengan cara konveksi selama 60 menit tanpa membatasi suhu pasien sampai suhu $36^{\circ} \mathrm{C}$. Suhu sebelum perlakuan $34,68^{\circ} \mathrm{C}$ dan sesudah perlakuan $36,23^{\circ} \mathrm{C}$ dengan peningkatan $1,54^{\circ} \mathrm{C}$. Berdasarkan hasil tersebut menunjukkan lampu penghangat lebih cepat menaikkan suhu tubuh, tetapi mempunyai risiko kulit terbakar bila terlalu dekat dan kenaikan suhu tubuh dapat lebih lama jika terlalu jauh. Penggunaan selimut elektrik jauh lebih aman karena menggunakan panas melalui konveksi dengan mesin pemanas yang bisa diatur suhu dan sensor suhu panas untuk mengukur suhu udara yang keluar. 
Keterbatasan penelitian ini adalah kelompok kontrol tidak menerima pemanasan aktif alternatif lainnya, meskipun pasien menerima isolasi pasif dengan penggunaan selimut yang menjadi kenyataan di banyak layanan kesehatan. Faktor-faktor yang dapat mempengaruhi penurunan suhu tubuh, seperti Body Mass Index (BMI) dan banyaknya cairan infus yang masuk selama proses operasi juga tidak dihitung. Keterbatasan lainnya yaitu untuk penggunaan obat-obatan yang dianggap mampu untuk mengatasi risiko hipotermia selama anestesi spinal, seperti golongan phenylephrine yang digunakan dalam kedua kelompok tidak dilaporkan (Bernardis, et al, 2016).

\section{KESIMPULAN}

1. Terdapat peningkatan suhu tubuh sebelum dan sesudah penggunaan selimut elektrik pada pasien post seksio sesarea di ruang pemulihan RSUD Dr. Tjitrowardojo Purworejo sebesar $1,54^{\circ} \mathrm{C}$.

2. Terdapat peningkatan suhu tubuh sebelum dan sesudah penggunaan selimut kain pada pasien post seksio sesarea di ruang pemulihan RSUD Dr. Tjitrowardojo Purworejo sebesar $0,85^{\circ} \mathrm{C}$

3. Hasil uji beda menunjukan penggunaan selimut elektrik lebih efektif dibandingkan penggunaan selimut kain terhadap peningkatan suhu tubuh pada pasien post seksio sesarea di ruang pemulihan RSUD Dr. Tjitrowardojo Purworejo.

\section{SARAN}

Berdasarkan kesimpulan tersebut maka peneliti memberikan saran agar RSUD Dr. Tjitrowardojo dapat mempertimbangkan dan menjadikan penggunaan selimut elektrik sebagai standar prosedur operasional dalam tindakan keperawatan dalam mengatasi hipotermi di ruang pemulihan kamar operasi.

\section{DAFTAR PUSTAKA}

Bernardis, R.C.G., et al. (2016). Perioperative warming with a thermal gown prevents maternal temperature loss during elective cesarean section A randomized clinical trial. Braz J Anesthesiol, 66(5), 451-455.

Kesuma, I.G.B.I.W., Kusumawati, P., dan Saputra, I. . (2013). The Differences in Effectiveness of Granting Thick Blankets and Heating Lamps in Sectio Caesarea Post-Surgery Patients who Undergo Hypothermia in the OK Recovery Room in Sanjiwani District Hospital Gianyar. Open Journal System Universitas Udayana, 1(2).

Lowdernilk, D. . (2010). Maternity Nursing. Maryland: Mosby.

Myles. (2009). Buku Ajar Bidan. Jakarta: ECG.

Robinson, J. . (2012). Critical Care Nursing. Norristown: Lippincott Williams.

Saifuddin, A. B. (2010). Ilmu Kebidanan. Jakarta: PT Bina Pustaka Sarwono Prawirohardjo.

Sessler, D. (2014). Temperature monitoring: the consequences and prevention of mild perioperative hypothermia. South Afr J Anaesth Analg, 20, 25-31.

Shen, J., Wang, Q., Zhang, Y., Wang, X., Shi, P. (2015). Combination of warming blanket and prewarmed intravenous infusion is effective for rewarming in infants with postoperative hypothermia in China. J Paediatr Anaesth, 25(11), 1139-1143.

Sjamsuhidajat dan De Jong. (2010). Buku Ajar Ilmu Bedah. Jakarta: ECG.

Smeltzer, C. . (2002). Buku Ajar Keperawatan Medikal Bedah. Jakarta: ECG.

Torossian, A., et al. (2016). Active perioperative patient warming using a self-warming blanket (BARRIER EasyWarm) is superior to passive thermal insulation: a multinational, multicenter, randomized trial. J Clin Anesth, 34, 547-554.

Wiknjosatro, H. (2007). Ilmu Bedah Kebidanan. Jakarta: Yayasan Bina Pustaka. 